\title{
Antioxidant Responses of Radiation-induced Dwarf Mutants of Bermudagrass to Drought Stress
}

\author{
Shaoyun Lu, Zhongcheng Wang, Yuejing Niu, and Zhenfei Guo ${ }^{1}$ \\ Biotechnology Laboratory, College of Life Science, South China Agricultural University, \\ Guangzhou 510642, China \\ Bingru Huang
Department of Plant Biology and Pathology, Cook College, Rutgers University, New Brunswick,
NJ 08901
}

\begin{abstract}
AdDitional InDex words. ascorbic acid, ascorbate-peroxidase, breeding, catalase, Cynodon dactylon, glutathione, superoxide dismutase, turfgrass

Abstract. Improving the drought tolerance of widely used bermudagrass [Cynodon dactylon (L.) Pers. var. dactylon] is important for water conservation and producing quality turf with limited irrigation. Mutants of bermudagrass were generated using gamma-ray irradiation with an aim toward developing dwarf and drought-resistant bermudagrass. The objectives of this study were to compare morphological characteristics between radiationinduced mutants and the wild-type of bermudagrass and to determine antioxidant responses associated with changes in drought resistance in the bermudagrass mutants. Three mutant lines (7-9, 10-5, and 10-12) that exhibit slow growth and good turf quality were chosen for this study. Plants were exposed to drought stress by withholding irrigation in a greenhouse. Mutant lines had lower canopy height, shorter internodes, and shorter leaves than the wild type under well-watered conditions. Under drought stress, all three dwarf mutant lines maintained higher relative water content and lower ion leakage and malondialdehyde content than the wild type. Antioxidant enzyme activities decreased in response to the drought stress in the mutant lines and the wild type, whereas nonenzymatic antioxidants increased under drought stress. Compared with the wild type, higher enzyme activities and antioxidant contents were maintained in mutant lines under drought stress. Our results indicated that bermudagrass mutants induced by gamma radiation exhibited dwarf characteristics and improved drought resistance, which was associated with maintenance of higher levels of antioxidant enzyme activities and nonenzymatic antioxidant contents.
\end{abstract}

Drought stress is a major factor limiting turfgrass growth in semiarid and arid regions across the world. It becomes more important during the summer months when evapotranspiration demand is increased. Radiation-induced mutations have been used to create genetic diversity and to improve plant tolerance to biotic and abiotic stresses in various major seed-propagated crops (Ahloowalia and Maluszynski, 2001). Radiation-induced mutations have also been used in generating forage grasses and turfgrasses with alterations in various morphological traits. The most frequent mutant character from the irradiated plants is dwarfism. Gamma irradiation has been used to develop the dwarf-type bermudagrass cultivars TifEagle, Tift 94, and Tifway II (Burton, 1985; Hanna and Elsner, 1999; Hanna et al., 1997). Gamma-ray irradiation has also been used in the breeding of centipedegrass [Eremochloa ophiuroides (Munro) Hack.] and st. augustinegrass [Stenotaphrum secundatum S. (Walt.) Kuntze] (Busey, 1980; Dickens et al., 1981). Mutants of st. augustinegrass induced by gamma irradiation exhibited considerable growth retardation (Busey, 1980).

Recent studies with velvet bentgrass (Agrostis canina L.), colonial bentgrass (Agrostis capillaris L.), and creeping bentgrass (Agrostis stolonifera L.) indicated that slow-growing turfgrass may be able to survive drought stress for prolonged periods of time. This stress was associated with reduced water

Received for publication 28 Jan. 2008. Accepted for publication 11 Mar. 2008. This work was funded by grants from the National Basic Research Program of China (2007CB108905) and Guangdong Provincial Science and Technology Projects (2006B20201035).

${ }^{1}$ Corresponding author. E-mail: zhfguo@scau.edu.cn. use and increased osmotic adjustment and antioxidant activity (DaCosta and Huang, 2006, 2007; McCann and Huang, 2008). However, studies with tall fescue (Festuca arundinacea Schreb) found that dwarf-type tall fescue had lower drought resistance than the forage-type ('Kentucky-31') (Carrow, 1996; Huang and Gao, 1999; White et al., 1993). These studies have revealed interspecific and intraspecific variation in drought resistance in relation to turfgrass growth.

Bermudagrass is a warm-season grass widely used for turfgrass on home lawns, sports fields, and golf courses in warm climatic regions. Bermudagrass grows most rapidly during the summer months. Rapid shoot growth increases demand on water, and therefore, frequent irrigation may be needed to maintain high-quality bermudagrass in areas with limited rainfall. In addition, bermudagrass requires frequent mowing during its active growing season. Due to limited water resources and increased energy costs, there is increasing demand for slow-growing turf with low irrigation requirements.

We developed several dwarf mutants lines of bermudagrass using gamma-ray irradiation. These are excellent germplasms for the investigation of whether dwarf turfgrass may exhibit improved drought resistance and for the analysis of physiological traits associated with drought resistance in dwarf bermudagrass. Previous studies in bermudagrass have examined cultivar variations in their overall turf performance in responses to irrigation schedule and drought stress, but differences in drought resistance between dwarf-type cultivars and common bermudagrass were not specifically evaluated (Baldwin et al., 2006; Jiang and Carrow, 2007; Lu et al., 2006). However, 
physiological mechanisms of bermudagrass tolerance to drought stress are not well understood. Drought tolerance involves various physiological responses, and antioxidative protection plays an important role in enhanced drought resistance in various plant species (Zhang and Kirkham, 1994; Noctor and Foyer, 1998). Reactive oxygen species (ROS) are induced during drought, which can cause cellular damage; however, plants develop enzymatic and nonenzymatic antioxidant activities to scavenge the ROS and protect cells from oxidative stress (Noctor and Foyer, 1998). The antioxidant defense system consists of several antioxidant enzymes such as superoxide dismutase (SOD), catalase (CAT), and ascorbate peroxidase (APX), and some nonenzyme antioxidants such as ascorbic acid (AsA) and glutathione (GSH), which protect plants from the deleterious effects of ROS that are produced when plants are exposed to abiotic stress (Noctor and Foyer, 1998).

The objectives of this study were to examine the morphological traits of radiation-induced dwarf mutants of bermudagrass and to determine water relations and antioxidant responses to drought stress associated with drought resistance for the dwarf bermudagrass mutants.

\section{Materials and Methods}

Plant materials and mutation treatment. A bermudagrass ecotype collected from the roadside in Guangzhou City, China, was planted at the experimental station of South China Agricultural University in Guangzhou, China. The wild-type ecotype exhibits good turf quality and rapid growth, requiring frequent mowing and irrigation. This wild type was used to generate mutants through gamma-ray irradiation. The stolons were cut into individual segments containing a single node. A total of 3000 stolon segments were irradiated with 70 to $100 \mathrm{~Gy}$ gamma rays using a ${ }^{60}$ Co source at the Irradiation Center, South China Agricultural University in 2003. The above dosages were used because 70 to 113 Gy of gamma irradiation was used successfully in creating bermudagrass mutants by others (Burton, 1985; Hanna and Elsner, 1999; Hanna et al., 1997; Powell et al., 1974). Irradiated stolons and nonirradiated stolons (wild type) were planted in the soil mixture of peat and perlite (3 : 1, by volume) for regeneration in a greenhouse under natural light conditions. About 100 plants regenerated from irradiated stolons exhibited shorter internodes and slower growth compared with the wild-type plants. They were transplanted to the field for further observation of growth habits in 2003. A total of 13 lines exhibited dwarf characteristics in the field from 2003 to 2005 . Among them, three lines (7-9, 10-5, and 10-12) exhibited slow growth and good turf quality and were selected for further examination. The three mutant lines and the wild-type plants were then transplanted to plastic pots (10 cm in diameter and $15 \mathrm{~cm}$ in depth) containing a mixture of peat and perlite ( $3: 1$, by volume) in the greenhouse. Plants were allowed to grow for at least 2 months in a greenhouse at temperatures of $20{ }^{\circ} \mathrm{C}$ to $30{ }^{\circ} \mathrm{C}$ under natural sunlight with a photoperiod of about 13 to $14 \mathrm{~h}$ before treatments were imposed. During the establishment period, plants were irrigated daily until soil was fully saturated, mowed at $2.5 \mathrm{~cm}$ weekly, and fertilized biweekly with $50 \mathrm{~mL}$ of soluble fertilizer of $15 \mathrm{~N}-6.6 \mathrm{P}-12.5 \mathrm{~K}$ at $3 \mathrm{~g} \cdot \mathrm{L}^{-1}$.

EVALUATION OF GROWTH CHARACTERISTICS. Growth characteristics were evaluated from well-watered plants, and 10 plants per pot were used for measurements. The second fully expanded leaves were used for the measurement of length and leaf width. The length of top three internodes in a stolon was measured to determine average internode length. For evaluation of shoot vertical growth, canopy height was measured at $14 \mathrm{~d}$ after mowing before next schedule of mowing.

EVALUATION OF DROUGHT RESISTANCE. Irrigation was withheld for $8 \mathrm{~d}$ under natural sunlight with a photoperiod of about 13 to $14 \mathrm{~h}$ in the greenhouse at temperatures ranging from $30{ }^{\circ} \mathrm{C}$ to $35^{\circ} \mathrm{C}$ to create the drought treatment. Five pots $(10 \mathrm{~cm}$ diameter and $15 \mathrm{~cm}$ deep) were used as replications for each plant line, which were arranged as a completely randomized design.

Relative water content (RWC) and ion leakage were determined from the leaves of pot plants as we described before (Lu et al., 2006). For measurement of RWC, fresh leaves were weighed $\left(\mathrm{W}_{\mathrm{f}}\right)$ and immersed in water overnight until the weight of the leaves was constant. The water-saturated leaves were weighed $\left(\mathrm{W}_{\mathrm{S}}\right)$ and then dried for $24 \mathrm{~h}$ at $80{ }^{\circ} \mathrm{C}$ for determinations of the dry weight $\left(\mathrm{W}_{\mathrm{d}}\right)$. RWC was calculated by the formula: $\mathrm{RWC}=\left(\mathrm{W}_{\mathrm{f}}-\mathrm{W}_{\mathrm{d}}\right) /\left(\mathrm{W}_{\mathrm{S}}-\mathrm{W}_{\mathrm{d}}\right) \times 100$.

For measurement of ion leakage, leaf samples were rinsed with distilled water and immersed in $10 \mathrm{~mL}$ of distilled water for $12 \mathrm{~h}$. The conductivity $\left(\mathrm{S} \cdot \mathrm{cm}^{-1}\right)$ of the solution $\left(\mathrm{R}_{1}\right)$ was measured using a conductivity meter (model DDS-11A; Shanghai Leici Instrument, Shanghai, China). Samples were then heated in boiling water for $20 \mathrm{~min}$ and then cooled to room temperature. The conductivity of killed tissues $\left(\mathrm{R}_{2}\right)$ was again measured. Ion leakage was calculated as the ratio of $R_{1}$ to $R_{2}$.

Measurement OF EVAPOTRANSPIRATIONAL WATER LOSS. Plants were fully irrigated in the evening and placed in a greenhouse overnight. The initial weight of plants plus soil $\left(\mathrm{W}_{1}\right)$ was recorded the next morning. The weight of the plants plus soil $\left(\mathrm{W}_{\mathrm{n}}\right)$ was recorded daily for $8 \mathrm{~d}$. Evapotranspirational water loss per pot per day was calculated as the difference of $\mathrm{W}_{\mathrm{n}-1}$ minus $\mathrm{W}_{\mathrm{n}}$.

Measurement of SoIL Water content. Soil samples were taken from each pot at different days during drought stress and fresh weight was determined $\left(\mathrm{W}_{1}\right)$. The soil was then dried for $24 \mathrm{~h}$ at $80^{\circ} \mathrm{C}$ for the determination of dry weight $\left(\mathrm{W}_{2}\right)$. Soil water content was calculated by the formula: $\left(\mathrm{W}_{1}-\mathrm{W}_{2}\right) /\left(\mathrm{W}_{2}\right) \times$ 100. To avoid the influence on plants by sampling, each pot was used only once during the experiments.

DETERMINATIONS OF MALONDIALDEHYDE (MDA) AND ENZYME ACTIVITIES. Fresh leaves $(0.5 \mathrm{~g})$ were ground in a mortar and pestle in $5 \mathrm{~mL}$ of $50 \mathrm{~mm}$ phosphate buffer $\left(\mathrm{pH} \mathrm{7.8)}\right.$ at $4{ }^{\circ} \mathrm{C}$. The homogenate was centrifuged at $13000 \mathrm{~g}_{\mathrm{n}}$ for $15 \mathrm{~min}$. The supernatant was recovered for determinations of MDA, SOD, and CAT activity.

MDA content was determined by using a spectrophotometer (model ultraviolet-2010; Hitachi Instruments, Inc., San Jose, CA) as previously described (Guo et al., 2005). The concentration of MDA was calculated using a coefficient of absorbance of $155 \mathrm{~mm} \cdot \mathrm{cm}^{-1}$. Activities of SOD and CAT were determined as described by Zhou et al. (2005). For determination of SOD activity, the $3-\mathrm{mL}$ reaction solution contained $13 \mu \mathrm{M}$ methionine, $63 \mu \mathrm{M} \rho$-nitroblue tetrazolium chloride (NBT), $1.3 \mu \mathrm{M}$ riboflavin, $50 \mathrm{~mm}$ phosphate buffer $(\mathrm{pH} 7.8)$, and $50 \mu \mathrm{L}$ of the enzyme extract. The reaction solution was incubated for $10 \mathrm{~min}$ under fluorescent light $\left(80 \mu \mathrm{mol} \cdot \mathrm{m}^{-2} \cdot \mathrm{s}^{-1}\right)$. Absorbance was determined at $560 \mathrm{~nm}$ by using a spectrophotometer (model ultraviolet-2010; Hitachi Instruments, Inc.). 
One unit of SOD activity was defined as the amount of enzyme required for inhibition of photochemical reduction of NBT by $50 \%$. For determination of CAT activity, the $3-\mathrm{mL}$ reaction solution contained $15 \mathrm{mM} \mathrm{H}_{2} \mathrm{O}_{2}, 50 \mathrm{~mm}$ phosphate buffer ( $\mathrm{pH} 7.0$ ), and $50 \mu \mathrm{L}$ of the enzyme extract. The reaction was initiated by adding the enzyme extracts, and the decreased absorbance of $\mathrm{H}_{2} \mathrm{O}_{2}$ (extinction coefficient $0.0394 \mathrm{mM} \cdot \mathrm{cm}^{-1}$ ) within $1 \mathrm{~min}$ at $240 \mathrm{~nm}$ was recorded. One unit of CAT activity was defined as the amount of enzyme required for catalyzing the conversion of $1 \mu \mathrm{mol} \mathrm{H}_{2} \mathrm{O}_{2}$ into water per minute.

Ascorbate-peroxidase activity was determined as described by Zhou et al. (2005). Leaves $(0.5 \mathrm{~g})$ were ground in $3 \mathrm{~mL}$ of extraction solution containing $50 \mathrm{~mm}$ phosphate buffer (pH 7.0), $2 \mathrm{~mm}$ AsA, and $5 \mathrm{~mm}$ EDTA using a mortar and pestle at $4{ }^{\circ} \mathrm{C}$. The homogenate was centrifuged for $15 \mathrm{~min}$ at $13,000 \mathrm{~g}_{\mathrm{n}}$. The supernatants were used for assays of enzyme activity. The $3-\mathrm{mL}$ reaction solution of APX contained $50 \mathrm{~mm}$ phosphate buffer ( $\mathrm{pH}$ 7.0), $0.5 \mathrm{~mm}$ AsA, $0.1 \mathrm{~mm} \mathrm{H}_{2} \mathrm{O}_{2}$, and $0.1 \mathrm{~mL}$ enzyme extracts. APX activity was calculated by following the decrease in absorbance of AsA (extinction coefficient $2.8 \mathrm{~mm} \cdot \mathrm{cm}^{-1}$ ) within $1 \mathrm{~min}$ at $290 \mathrm{~nm}$. One unit of APX activity was defined as the amount of enzyme required for catalyzing the oxidation of $1 \mu \mathrm{mol}$ AsA per minute.

Determinations of AsA and GSH. For AsA and GSH analysis, fresh leaves $(1 \mathrm{~g})$ were ground in a mortar with pestle in $5 \mathrm{~mL}$ of $5 \%$ trichloroacetic acid at $4{ }^{\circ} \mathrm{C}$. The homogenates were centrifuged at $13,000 \mathrm{~g}_{\mathrm{n}}$ for $15 \mathrm{~min}$. AsA and GSH was determined as described by Guo et al. (2006). For determination of AsA, $200 \mu \mathrm{L}$ of $\mathrm{NaH}_{2} \mathrm{PO}_{4}$ buffer (150 mM, pH 7.4) and $200 \mu \mathrm{L}$ of water were added to $200 \mu \mathrm{L}$ of extract. The mixture was vortexed and incubated at room temperature for $30 \mathrm{~s}$, and the following were then added: $400 \mu \mathrm{L}$ of $10 \%(\mathrm{w} / \mathrm{v})$ trichloroacetic acid, $400 \mu \mathrm{L}$ of $44 \%$ (v/v) $\mathrm{H}_{3} \mathrm{PO}_{4}, 400 \mu \mathrm{L}$ of $4 \%(\mathrm{w} / \mathrm{v})$ bipyridyl in $70 \%(\mathrm{v} / \mathrm{v})$ ethanol, and $200 \mu \mathrm{L}$ of $3 \%(\mathrm{w} / \mathrm{v}) \mathrm{FeCl}_{3}$. After vortexing, samples were incubated at $37^{\circ} \mathrm{C}$ for $60 \mathrm{~min}$ and the absorbance at $525 \mathrm{~nm}$ was recorded. AsA concentration was calculated by comparison with standard curve in the range 0.1 to $0.5 \mathrm{~mm}$ of AsA. For determination of GSH, $0.2 \mathrm{~mL}$ of extract was neutralized with $2.6 \mathrm{~mL}$ of $150 \mathrm{~mm} \mathrm{NaH}{ }_{2} \mathrm{PO}_{4}(\mathrm{pH} 7.4)$ and incubated with $0.2 \mathrm{~mL}$ of $5,5^{\prime}$-dithio-bis(2-nitrobenzoic acid) (75.3 $\mathrm{mg}$ of 5,5' -dithio-bis(2-nitrobenzoic acid was dissolved in $30 \mathrm{~mL}$ of $100 \mathrm{~mm}$ phosphate buffer, $\mathrm{pH} 6.8$ ) at $30^{\circ} \mathrm{C}$ for $10 \mathrm{~min}$. Absorbance was determined at $412 \mathrm{~nm}$ and the GSH concentration was calculated by comparison with standard curve.

ExPERIMENTAL DESIGN AND STATISTICAL ANALYSIS. The experiment consisted of three dwarf mutant lines and a wild-type control of bermudagrass exposed to drought stress arranged in a completely randomized design. Repeated measurements of RWC, ion leakage, leaf morphology, and the antioxidant defense system were made on five pots as replicates. Statistical significance of data was tested using the analysis of variance procedure (SAS Institute, Cary, NC). Least significance test (LSD) at the $0.05 P$ level was used to detect the differences among means.

\section{Results}

Growth Characteristics of MUtANT Lines. Three mutant lines of bermudagrass (7-9, 10-5, and 10-12) generated from the gamma ray-irradiated stolons exhibited a more dwarf habit and had a more compact turf canopy than the wild type (Fig. 1). In addition, mutant line 7-9 exhibited creeping growth.

The canopy height at $14 \mathrm{~d}$ after mowing is shown in Fig. 2A. The mutant lines had slower vertical growth than the wild-type control. Canopy height was lower by $47 \%, 24 \%$, and $21 \%$, respectively, in the lines 7-9, 10-5, and 10-12 compared with the wild type (Fig. 2A). Mutant lines 10-5 and 10-12 had shorter internodes (Fig. 2B), and all three lines had short leaves (Fig. $2 \mathrm{C}$ ) compared with the wild type. No significant difference in leaf width was observed between the mutant lines and the wild type (data not shown).

RESPONSES OF WATER STATUS, ION LEAKAGE, AND LIPID PEROXIDATION TO DROUght STREss. The wild-type plants exhibited wilting after withholding irrigation at day 4 and serious wilting at day 6 after withholding irrigation, whereas the mutant lines maintained fully turgid condition at day 4 and showed slight wilting at day 6 . The wild-type plants were completely desiccated by day 8 , while leaves of mutant lines maintained partial turgidity. Mutant lines and the wild type had similar RWC (Fig. 3A) and ion leakage (Fig. 3B) under wellwatered conditions. RWC decreased gradually in the wild type and mutant lines after $4 \mathrm{~d}$ of drought treatment, and it was maintained at a significantly higher level in the mutant lines (7-9, 10-5, and 10-12) than in the wild-type control. Line 7-9 had the highest RWC among the three mutant lines (Fig. 3A). In contrast, ion leakage and MDA increased gradually in response to the drought stress treatment. The mutant lines (7-9, 10-5, and 10-12) had significantly lower levels of ion leakage and MDA than the wild-type control, and line 7-9 had the lowest ion leakage and MDA during drought stress (Fig. 3, B and C).

The daily evapotranspirational water loss exhibited no difference among the tested mutant lines and the wild-type control. Its decrease at days 2 and 3 might reflect the influence of weather, as the plants were grown under natural sunlight, whereas the great decrease at days 7 and 8 depended upon the absence soil water (Fig. 4A). By withholding irrigation, soil water content decreased gradually from the initial level of $\approx 40 \%$ under well-watered conditions to $10 \%$ by $8 \mathrm{~d}$ of drought

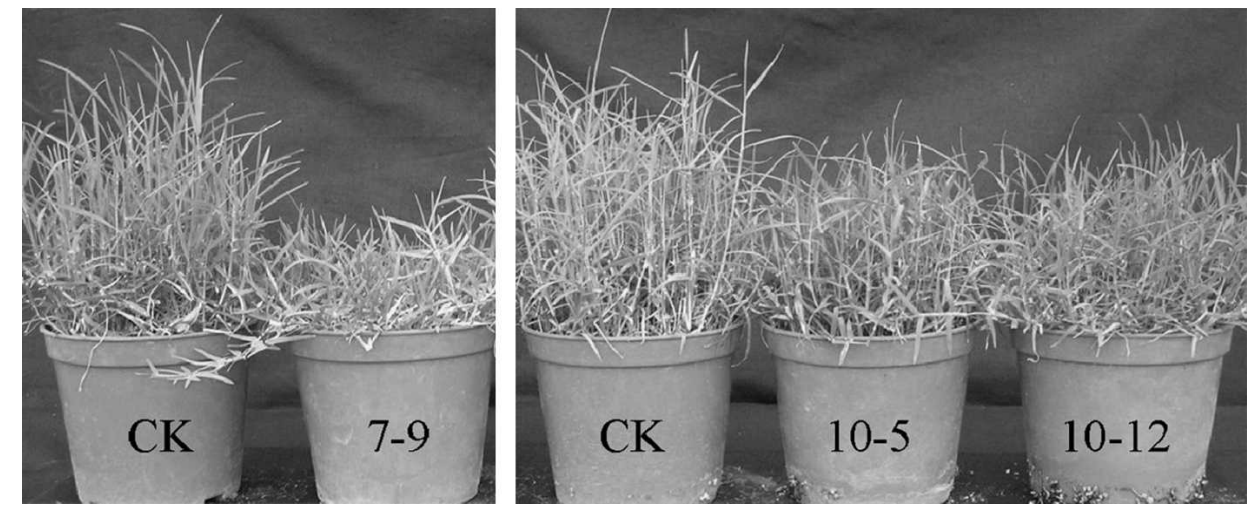

Fig. 1. The dwarf mutant lines (7-9, 10-5, and 10-12) in comparison with the wild-type control (CK) of bermudagrass. The plants were mowed at $2.5 \mathrm{~cm}$ above the soil surface. The photos were taken $14 \mathrm{~d}$ after mowing. 

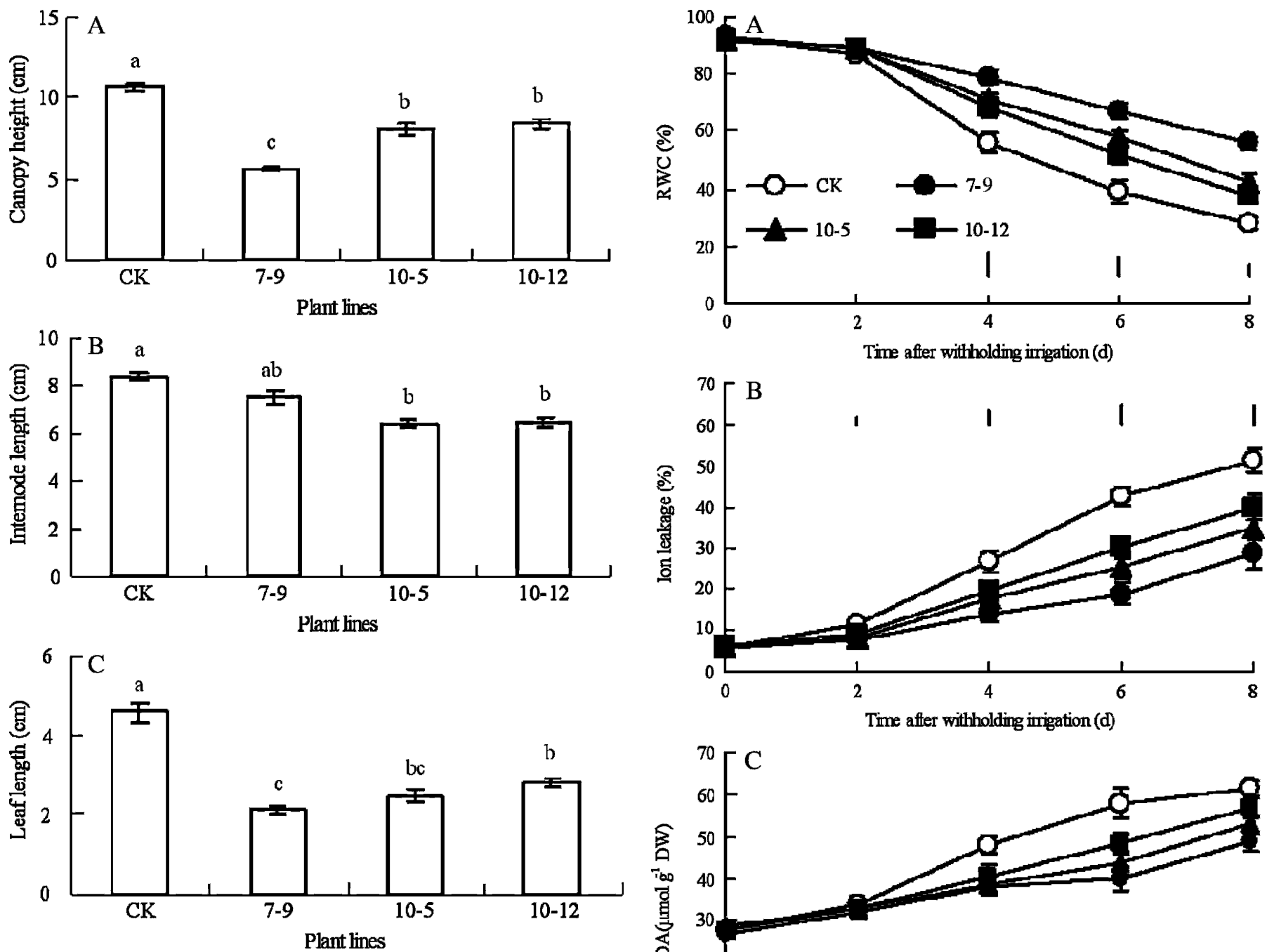

Fig. 2. The canopy height (A), internode length (B), and leaf length (C) of the dwarf mutant lines (7-9, 10-5, and 10-12) in comparison with the wild-type control (CK) of bermudagrass at day 14 after mowing. The data were the means from five independent measurements and were measured at day 14 postmowing.

stress. Soil water content was maintained at the same levels for the three dwarf mutant lines and the wild-type control during the $8 \mathrm{~d}$ of drought period (Fig. 4B).

RESPONSES OF ANTIOXIDANTS TO DROUGHT STRESS. Antioxidant responses to drought stress were compared between the three mutant lines and the wild type. SOD activity was significantly higher in line 7-9 than the wild-type control, but showed no difference between the wild type and the other two mutants under well-watered conditions (0 d; Fig. 5A). During drought treatment, SOD activity exhibit a gradual decrease trend in the wild type, while it remained relatively unchanged in all three mutant lines and was significantly higher than the wild-type line at 2 to $8 \mathrm{~d}$ of treatments (Fig. 5A). Before drought stress, CAT and APX activities were significantly higher in mutants 7-9 and 10-5 than in the wild-type control. They exhibited decrease trend after drought stress in the wild type and three mutant lines (Fig. 5, B and C). Mutant line 7-9 consistently maintained significantly higher CAT and APX activities during the 8-d drought period than the wild type, while the other two mutant lines had a significantly higher level

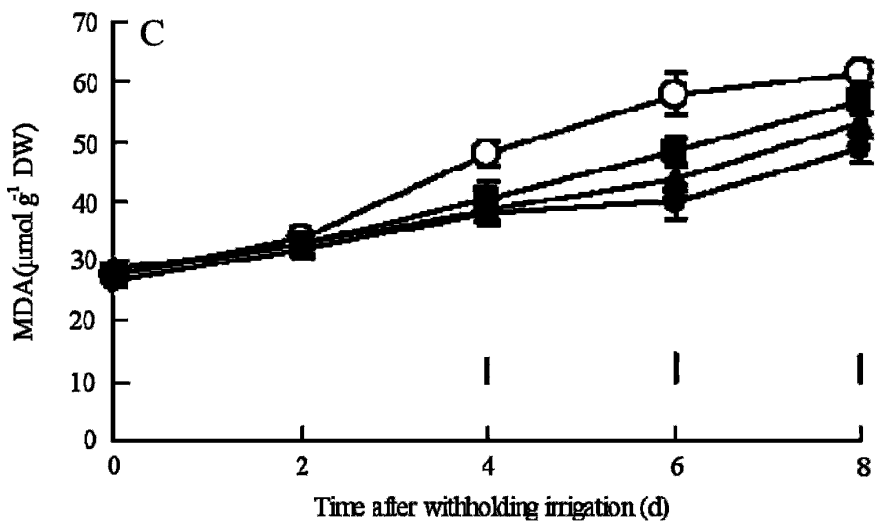

Fig. 3. Relative water content (RWC; A), ion leakage (B), and malondialdehyde (MDA) content $(\mathrm{C})$ of the dwarf mutant lines $(7-9,10-5$, and 10-12) in comparison with the wild-type control (CK) of bermudagrass under drought stress. Vertical bars at the top or bottom of the figure indicate LSD values $(P=$ 0.05 ) for group comparison at a given day of treatment.

of CAT or APX than the wild type only on some of the days during drought.

AsA and GSH contents were similar among the tested plants under well-watered conditions (0 d; Fig. 6, A and B). Both AsA and GSH content increased during drought stress in all plants. The three mutant lines had significantly higher AsA and GSH content than the wild type after $4 \mathrm{~d}$ of drought stress (Fig. 6, A and B).

\section{Discussion}

Three mutant lines of bermudagrass generated from the gamma ray-irradiated stolons exhibited dwarf characteristics (shorter internode and leaves, and lower canopy height). 

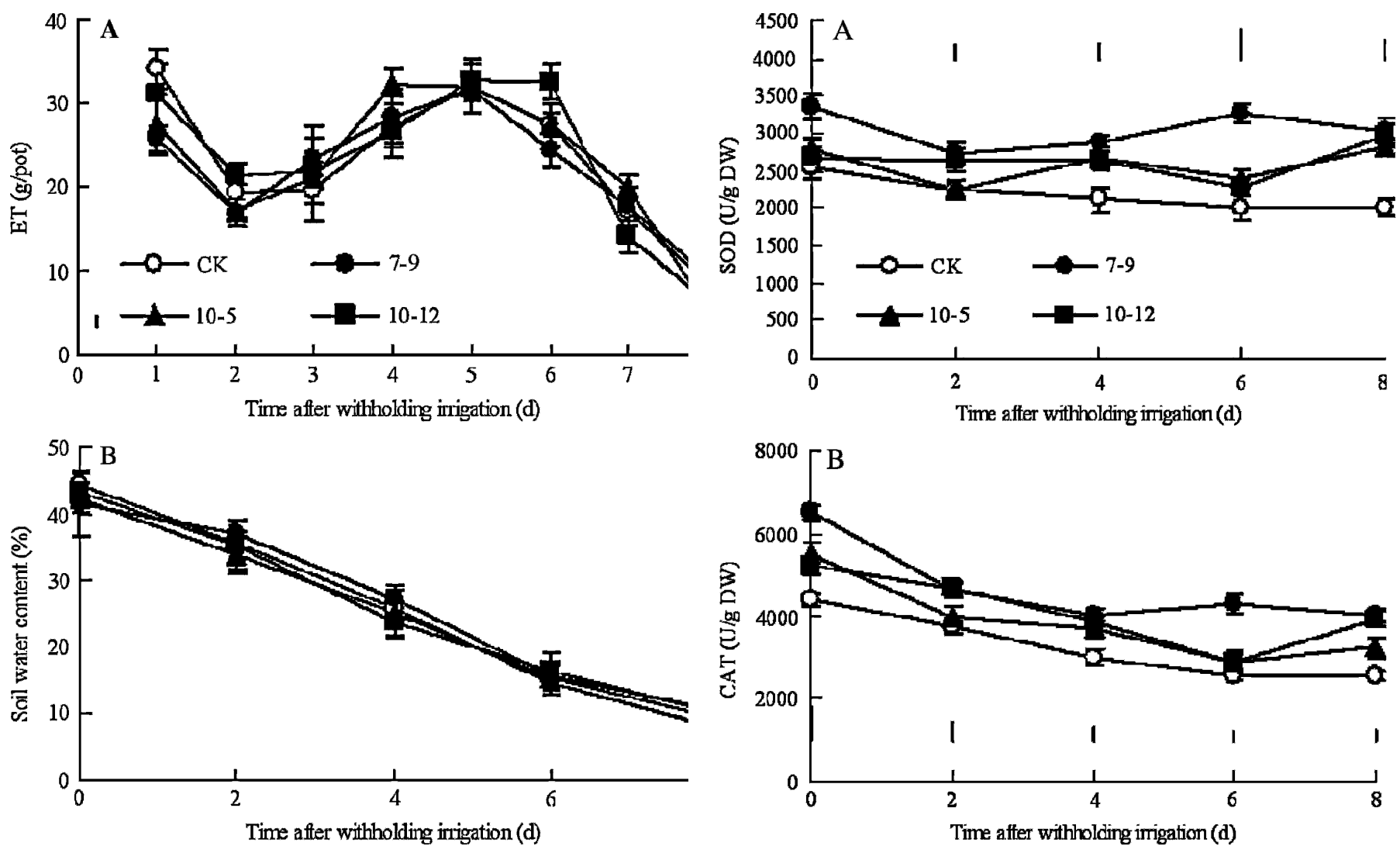

Fig. 4. Evapotranspirational water loss (A) and soil water content (B) of the dwarf mutant lines (7-9, 10-5, and 10-12) in comparison with the wild-type control (CK) of bermudagrass under drought stress. No vertical bars (LSD values $)$ in the figure indicate that the data were not significantly different $(P=$ 0.05 ) for group comparison at a given day of treatment.

Shorter canopy height and internode in the mutants may result in a more dwarf and denser turf. Among the mutant lines, 7-9 was more dwarf than the mutant lines 10-5 and 10-12, indicating it had the slowest vertical growth and might need the lowest frequencies of mowing; $10-5$ and 10-12 had slightly shorter internode length, indicating they might produce a denser turf than 7-9. Previous studies using gamma radiation have developed dwarf bermudagrass cultivars (Burton, 1985; Hanna and Elsner, 1999; Hanna et al., 1997) and st. augustine cultivars (Busey, 1980). This study, in combination with other reports, demonstrates that irradiation mutation is a feasible means to generate morphologically diverse turfgrass germplasm.

It has been proposed that the slow-growing trait in dwarf turfgrasses may lead to low water use (Burton, 1985; Hanna and Elsner, 1999; Hanna et al., 1997). However, in our study, the evapotranspirational water loss was not significantly different between the mutant lines and the wild-type control during drought stress, which led to no significant difference in soil water content between the mutants and the wild type. This might be a result of a lower internode length in the mutants, which may result in an increased density of turf, although the turf density of pot plants was not measured in the present study. RWC reflects water status of plants, whereas ion leakage reflects the injury of the plasmalemma. MDA is a product of membrane lipid peroxidation and is an index of the oxidative injury of plants. Higher RWC and lower ion leakage and MDA content were maintained in the mutant lines than in the wild

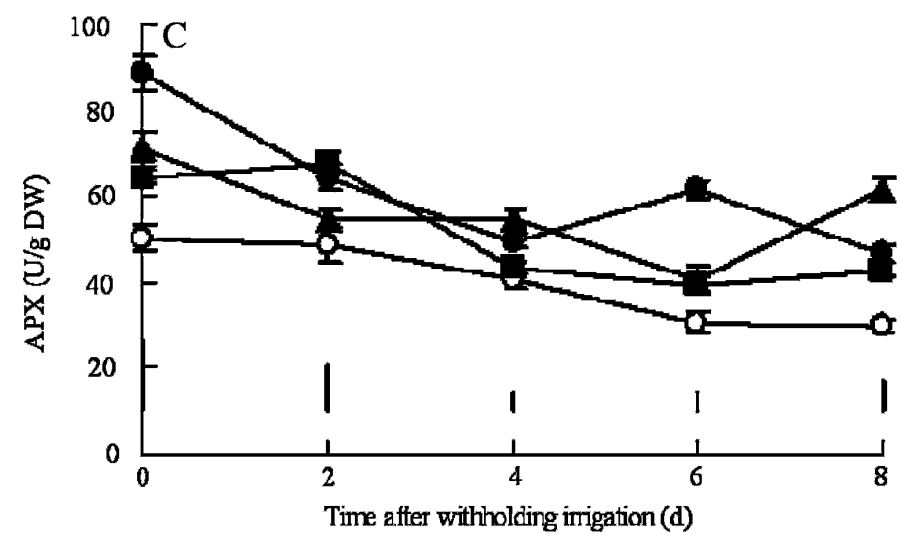

Fig. 5. The activities of (A) superoxide dismutase (SOD), (B) catalase (CAT), and (C) ascorbate-peroxidase (APX) in the dwarf mutant lines (7-9, 10-5, and 10-12) in comparison with the wild-type control (CK) of bermudagrass under drought stress. Vertical bars at the top or bottom of the figure indicate LSD values $(P=0.05)$ for group comparison at a given day of treatment. One unit of SOD activity was defined as the amount of enzyme required for inhibition of photochemical reduction of nitroblue tetrazolium chloride (NBT) by $50 \%$, whereas one unit of CAT or APX activity was defined as the amount of enzyme required for catalyzing the conversion of $1 \mu \mathrm{mol} \mathrm{H}_{2} \mathrm{O}_{2}$ or ascorbic acid (AsA) per minute.

type under drought stress, indicating that the mutants exhibited increased drought resistance in comparison with the wild type. As there is no difference in evapotranspirational water loss and soil water content between the mutants and their wildtype control, our results indicated that the enhanced drought resistance in the dwarf mutants of bermudagrass generated in our study could mainly be related to an increase of drought tolerance. 

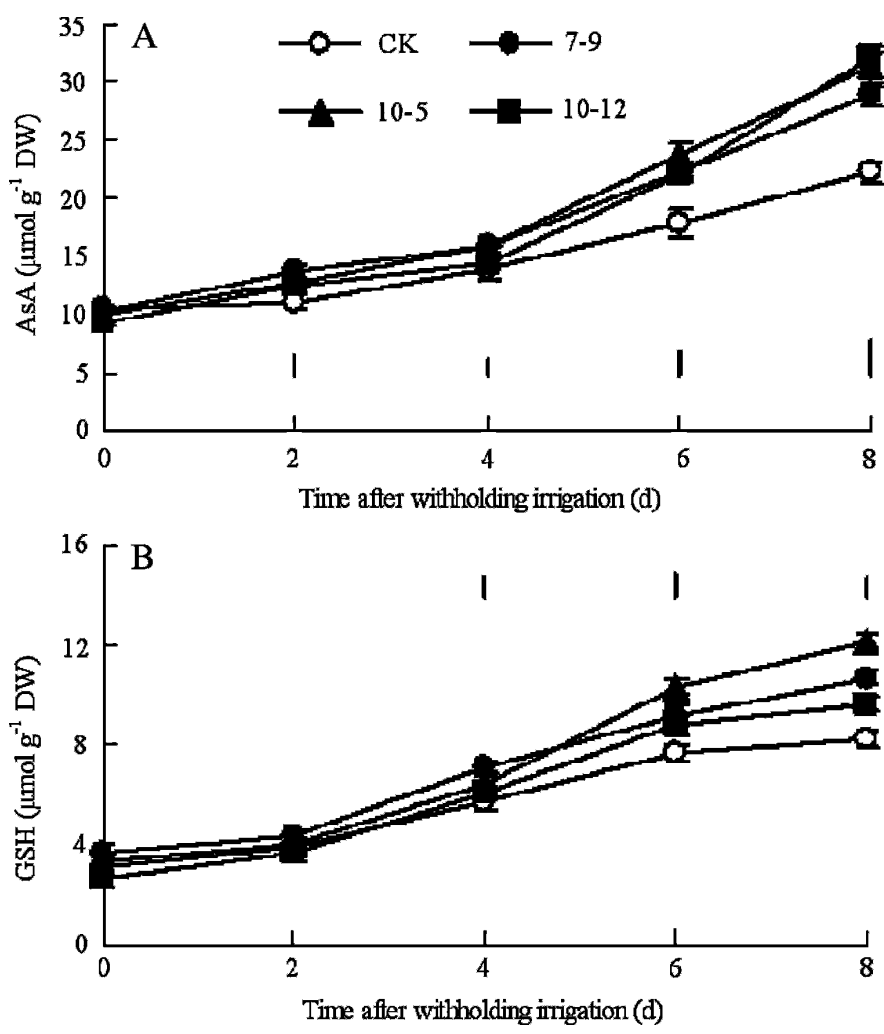

Fig. 6. The contents of (A) ascorbic acid (AsA) and (B) reduced glutathione (GSH) of the dwarf mutant lines (7-9, 10-5, and 10-12) in comparison with the wild-type control (CK) of bermudagrass under drought stress. Vertical bars at the top or bottom of the figure indicate LSD values $(P=0.05)$ for group comparison at a given day of treatment.

Much stress injury to plants, including drought, is associated with oxidative damage at the cellular level (Srivalli et al., 2003). Drought stress may change the balance between nonenzyme antioxidant defense and enzymatic defense reactions (Zhang and Kirkham, 1994). In the present study, the activities of SOD, CAT, and APX decreased in response to drought stress to a greater extent in the wild type than in the mutant line, suggesting that the antioxidant enzymes in the wild type were more responsive to drought stress than those in the mutant line. The association of drought injury with a decrease in antioxidant enzyme activities has been observed in the cool-season turfgrasses (Jiang and Huang, 2001). Nevertheless, higher activities of antioxidant enzymes were associated with the increased drought resistance in the mutant lines. The mutant lines had higher activities of CAT and APX than the wild-type control before drought stress, indicating that they have a constitutively higher expression of these antioxidant enzymes, which may contribute their higher drought resistance. Higher activities of SOD, CAT, and APX were observed in the cold-tolerant bermudagrass cultivar Riviera in comparison with the coldsensitive cultivar Princess-77 during cold adaptation, which contributed to the cold tolerance of bermudagrass (Zhang et al., 2006). AsA and GSH contents increased in the wild-type control and the mutant lines in response to drought stress. It has been previously shown that higher levels of AsA and GSH were positively related to drought tolerance in drought-tolerant cultivars of rice (Oryza sativa L.), and that decreased levels of antioxidants were associated with drought sensitivity in drought-sensitive cultivars (Guo et al., 2006). The higher levels of AsA and GSH in the mutant lines may improve their ability to scavenge the accumulated ROS and, therefore, may protect plants from oxidative damage under drought stress.

In summary, our study demonstrated that dwarf mutants of bermudagrass generated through gamma irradiation exhibited increased drought resistance compared with the wild type. Improved drought resistance of the dwarf mutants was associated with the maintenance of antioxidant enzyme activities and nonenzymatic antioxidants content under drought stress. Growth characteristics are the most evident traits in the mutants, which might result from a mutation of a locus that controls or is closely related to growth. The mutation also affected antioxidant enzyme activity. This can be confirmed by higher activities of SOD, CAT, and APX in 7-9 and higher activities of CAT and APX in 10-5 before drought stress.

\section{Literature Cited}

Ahloowalia, B.S. and M. Maluszynski. 2001. Induced mutations: A new paradigm in plant breeding. Euphytica 118:167-173.

Baldwin, C.M., H. Liu, L.B. McCarty, W.L. Bauerle, and J.E. Toler. 2006. Response of six bermudagrass cultivars to different irrigation intervals. HortTechnology 16:466-470.

Burton, G.W. 1985. Registration of Tifway II bermudagrass. Crop Sci. 25:364.

Busey, P. 1980. Gamma ray dosage and mutation breeding in st. augustinegrass. Crop Sci. 20:181-184.

Carrow, R.N. 1996. Drought avoidance characteristics of diverse tall fescue cultivars. Crop Sci. 36:371-377.

DaCosta, M. and B. Huang. 2006. Osmotic adjustment associated with variation in bentgrass tolerance to drought stress. J. Amer. Soc. Hort. Sci. 131:338-344.

DaCosta, M. and B. Huang. 2007. Changes in antioxidant enzyme activities and lipid peroxidation for bentgrass species in response to drought stress. J. Amer. Soc. Hort. Sci. 132:319-326.

Dickens, R., W.J. Johnston, and R.L. Haaland. 1981. Variability observed in centipedegrass grown from ${ }^{60} \mathrm{Co}$-irradiated seed. Agron. J. 73:674-676.

Guo, Z., W. Ou, S. Lu, and Q. Zhong. 2006. Differential responses of antioxidative system to chilling and drought in four rice cultivars differing in sensitivity. Plant Physiol. Biochem. 44:828-836.

Guo, Z., H. Tan, Z. Zhu, S. Lu, and B. Zhou. 2005. Effect of intermediates on ascorbic acid and oxalate biosynthesis of rice and in relation to its stress resistance. Plant Physiol. Biochem. 43:955962.

Hanna, W.W., R.N. Carrow, and A.J. Powell. 1997. Registration of Tift 94 bermudagrass. Crop Sci. 37:1012.

Hanna, W.W. and J.E. Elsner. 1999. Registration of TifEagle bermudagrass. Crop Sci. 39:1258.

Huang, B. and H. Gao. 1999. Physiological responses of diverse tall fescue cultivars to drought stress. HortScience 34:897-901.

Jiang, Y. and R.N. Carrow. 2007. Broadband spectral reflectance models of turfgrass species and cultivars to drought stress. Crop Sci. 47:1611-1618.

Jiang, Y. and B. Huang. 2001. Drought and heat stress injury to two cool-season turfgrasses in relation to antioxidant metabolism and lipid peroxidation. Crop Sci. 41:436-442.

Lu, S., Z. Wang, X. Peng, Z. Guo, G. Zhang, and L. Han. 2006. An efficient callus suspension culture system for triploid bermudagrass (Cynodon transvaalensis $\times C$. dactylon) and somaclonal variations. Plant Cell Tissue Organ Cult. 87:77-84.

McCann, S. and B. Huang. 2008. Drought responses of Kentucky bluegrass and creeping bentgrass as affected by abscisic acid and trinexapac-ethyl. J. Amer. Soc. Hort. Sci. 133:20-26.

Noctor, G. and C.H. Foyer. 1998. Ascorbate and glutathione: Keeping active oxygen under control. Annu. Rev. Plant Physiol. Plant Mol. Biol. 49:249-279. 
Powell, J.B., G.W. Burton, and J.R. Young. 1974. Mutations induced in vegetatively propagated turf bermudagrasses by gamma radiation. Crop Sci. 14:327-332.

Srivalli, B., G. Sharma, and R. Khanna-Chopra. 2003. Antioxidative defense system in an upland rice cultivar subjected to increasing intensity of water stress followed by recovery. Physiol. Plant. 119:503-512.

White, R.H., A.H. Bruneau, and T.J. Cowetl. 1993. Drought resistance of diverse tall fescue cultivars. Intl. Turf. Soc. Res. J. 7:607-613.
Zhang, X., E.H. Ervin, and A.J. LaBranche. 2006. Metabolic defense responses of seeded bermudagrass during acclimation to freezing stress. Crop Sci. 46:2598-2605.

Zhang, J. and M.B. Kirkham. 1994. Drought-stress-induced changes in activities of superoxide dismutase, catalase, and peroxidase in wheat species. Plant Cell Physiol. 35:785-791.

Zhou, B., Z. Guo, J. Xing, and B. Huang. 2005. Nitric oxide is involved in abscisic acid-induced antioxidant activities in Stylosanthes guianensis. J. Expt. Bot. 56:3223-3228. 